\title{
Improvement of computational abilities in computing environments with virtualization technologies
}

\author{
A. V. Bogdanov ${ }^{1, \mathrm{a}}$, Kyaw Zaya ${ }^{2, \mathrm{~b}}$, Pyae Sone Ko Ko ${ }^{2, \mathrm{c}}$ \\ ${ }^{1}$ Institute for High-performance computing and the integrated systems, St. Petersburg, 199397, Russia \\ 2 St.Petersburg State Marine Technical University, 3 Lotsmanskaya Str., St. Petersburg, 190008 Russia \\ E-mail: ${ }^{a}$ bogdanov@csa.ru, ${ }^{b}$ kyawzaya4436@gmail.com, ${ }^{c}$ pyaesonekoko@gmail.com
}

Received December 4, 2014

In this paper, we illustrates the ways to improve abilities of the computing environments by using virtualization, single system image (SSI) and hypervisor technologies' collaboration for goal to improve computational abilities. Recently cloud computing as a new service concept has become popular to provide various services to user such as multi-media sharing, online office software, game and online storage. The cloud computing is bringing together multiple computers and servers in a single environment designed to address certain types of tasks, such as scientific problems or complex calculations. By using virtualization technologies, cloud computing environment is able to virtualize and share resources among different applications with the objective for better server utilization, better load balancing and effectiveness.

Keywords: virtualization, hypervisor, shared memory system, single system image

\section{Усовершенствование вычислительных возможностей в вычислитель- ной среде с помощью технологий виртуализации}

\author{
А. В. Богданов, Кьяв Зайя, Пуае Сон Ко Ко \\ ${ }^{1}$ Института высокопроизводительных вычислений и Информационных Систем, \\ Россия, 199397, г. Санкт-Петербург \\ ${ }^{2}$ Санкт-Петербургский государственный морской технический университет, \\ Россия, 190008, г. Санкт-Петербург, ул. Лоиманская, д. 3
}

В этой работе мы показываем способы увеличения возможностей вычислительных сред с помощью виртуализации, единого системного образа (SSI) и коллаборации технологий гипервизора с целью улучшения вычислительных возможностей. В последнее время облачные вычисления как новое сервисное понятие, стали популярными для обеспечения различных сервисов для пользователя типа разделения мультимедиа, офисное on-line программное обеспечение, игры и on-line хранилища. Облачные вычисления объединяют множество компьютеров и серверов в единую среду, разработанную для обращения к определённым типам задач, таких как научные задачи или сложные вычисления. С помощью технологий виртуализации среда облачных вычислений способна виртуализировать и разделять ресурсы между различными приложениями с целью лучшего использования сервера, лучшего балансирования загрузки и эффективности.

Ключевые слова: виртуализация, гипервизор, система разделяемой памяти, единый системный образ Citation: Computer Research and Modeling, 2015, vol. 7, no. 3, pp. 499-504. 


\section{Introduction}

Now a day new technologies allow us to create relatively cheap multi-machine systems with shared computing resource, simplicity to manage heterogeneous resources and control large amount data transfer among them. Such systems provide relatively low computational cost, highly scalable, have high levels of reliability are proven tools for designing, debugging and performance analysis of parallel programs. The new approach is to combine virtualization technology with single system image. Since few years, virtual machines were offered enhanced resource management, using features such as live migration. SSI supports easier programming and administration for cluster environment. After evaluating different configurations, we show that combining the approaches allows us to better decisions challenges such as flexibility for the use of available resources and simplicity of use. In other terms, virtual machines add a level of management flexibility between the hardware and applications, while SSI provides an abstraction of distributed resources. Simultaneous use of both technologies could improve the overall platform resources, productivity and efficiency of the cluster running applications. Advantage of cloud computing is the ability to virtualize and share resources among different applications in order to ensure better utilization of the server [Al-Kiswany et al., 2011] [Nagarajan et al., 2007]. Cloud computing, a large distributed system that uses distributed resources to provide services to end-users through the implementation of several technologies. Virtualization technologies which are heavily relied on by the Cloud Computing environments provide the ability to transfer virtual machines (VM) between the physical systems using the technique of live migration mainly for improving the efficiency [Sabahi, 2012]. Dynamic server consolidation through live migration is an efficient way in cloud computing environments.

\section{Hypervisor}

A hypervisor, also known as a virtual machine monitor (VMM), is computer hardware platform virtualization software that allows several operating systems to share a single hardware host. Each operating system appears to have the host's processor, memory and resources to itself. The hypervisor is controlling the host processor and resources, distributing what is needed to each operating system in turn and ensuring that the guest operating systems or virtual machines are unable to disrupt each other [Yong, Network...]. In a virtual environment, the virtual machine monitor (VMM) is the master control program with the maximum privilege level, and the VMM manages one or more operating systems. Hypervisors are classified into two types:

Native hypervisors: Software systems that run directly on the host's software as a hardware control and guest operating system monitor. A guest operating system thus runs on another level above the hypervisor. This is the classic implementation of virtual machine architectures.

Host hypervisors: Software applications that run within a conventional operating system environment. Considering the hypervisor layer being a distinct software layer, guest operating systems thus run at the third level above the hardware.

\section{Virtualization}

Virtualization enables the consolidation and pooling of resources so that they can be distributed across a variety of applications to compensate for the limited resources and reduce growing business needs. Virtualization provides a logical abstraction of physical computing resources and creates computing environments that are not limited to the physical configuration or implementation.

\section{Virtualization Methods}

\section{Operating System-Based Virtualization}

Virtualization is enabled by a host operating system that supports multiple isolated and virtualized guest OS's on a single physical server with the characteristic that all are on the same operating 
system kernel with exclusive control over the hardware infrastructure. The host operating system can view and has control over the Virtual Machines [Sabahi, 2012] [Litty, 2005].

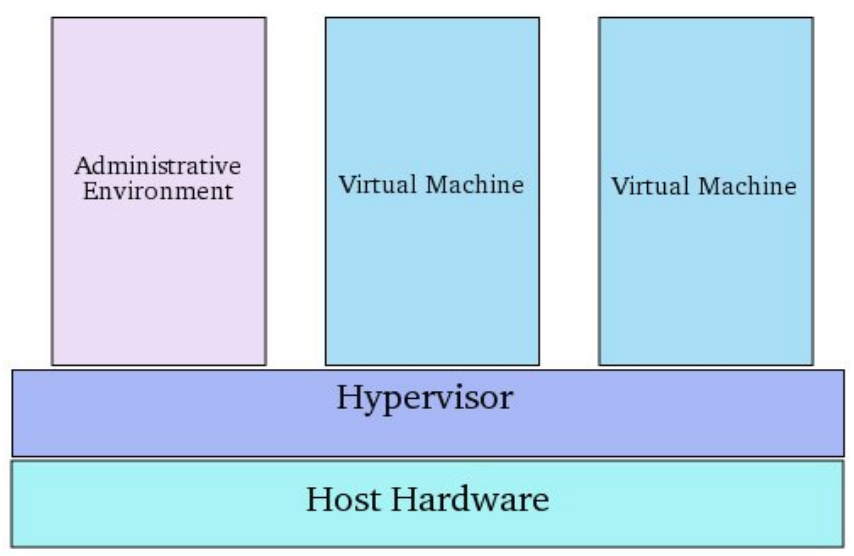

Fig. 1. Hypervisor (Virtual Machine Monitor)

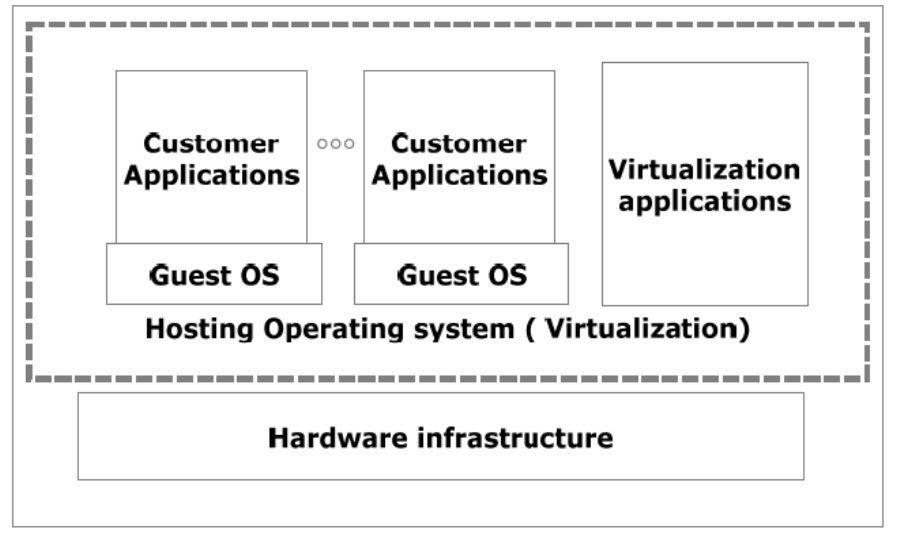

Fig. 2. Operation System-Based Virtualization

\section{Application-based virtualization}

An application-based virtualization is hosted on top of the hosting operating system. This virtualization application then emulates each VM containing its own guest operating system and related applications [Sabahi, 2012].

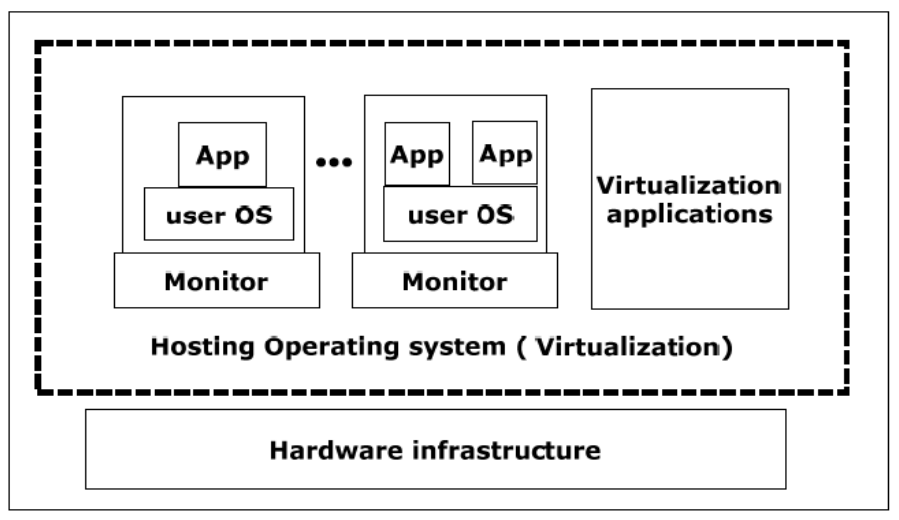

Fig. 3. Application-Based Virtualization

\section{Hypervisor-based virtualization}

The hypervisor is available at the boot time of machine in order to control the sharing of system resources across multiple VMs. Some of these VMs are privileged partitions which manage the virtu- 
alization platform and hosted Virtual Machines. In this architecture, the privileged partitions view and control the Virtual Machines. This approach establishes the most controllable environment and can utilize additional security tools such as intrusion detection systems [Sabahi, 2012; Litty, 2005].

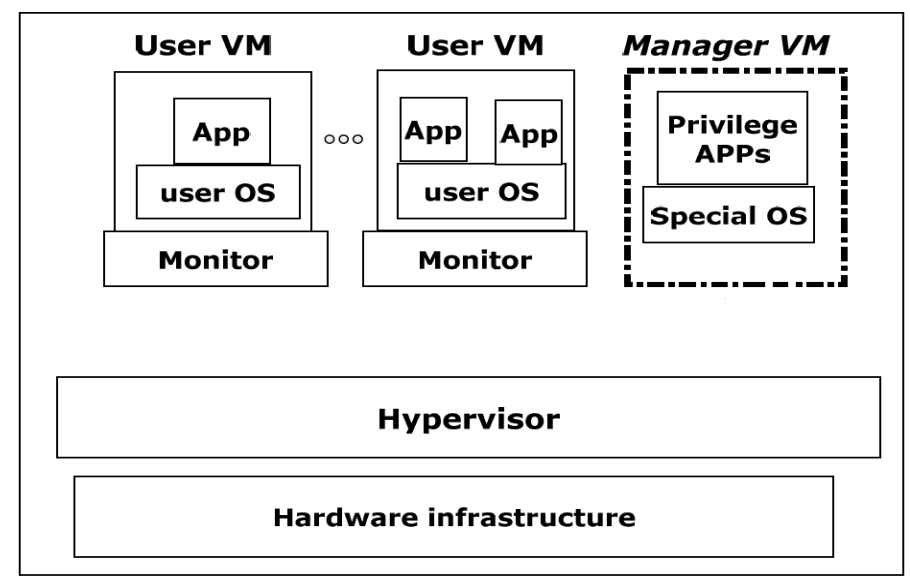

Fig.4. Hypervisor-Based Virtualization

\section{Single System Image}

SSI means that all the distributed resources are organized to a uniform unit for users, users can not be aware of the existence of every node that makes up of the computer system. SSI includes some attributes such as single memory space, single process space, single I/O space, single log on point, single file system, single loads management, and so on. The key attributes of SSI are single memory space and single process space [Rajkumar Buyya, 2001; Yong, Network...]. The SSI of a cluster can be implemented on the hardware level, the under-ware level, the middleware level and the application level.

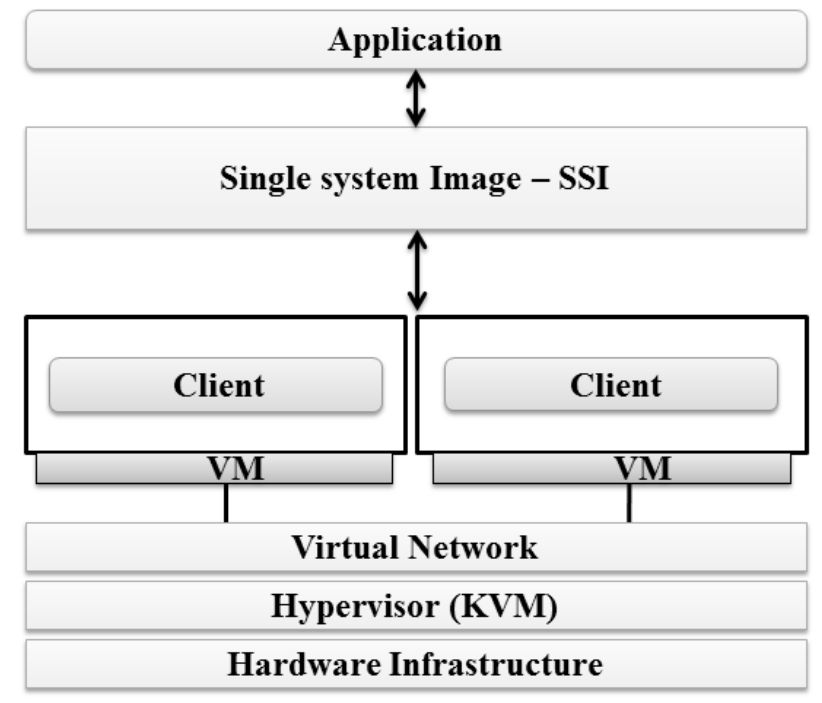

Fig.5. Integration of Single System Image and Virtualization

\section{Live Migration}

Transfers applications on a guest OS to any other healthy node and also provide the premigration mechanism where all the states are transferred before the application starts executing on the 
new healthy node. The sequence in which the live migration occurs is explained below [Desai, 2012; Nagarajan et al., 2007]:

(a) Pre Migration: Whenever the migration is initiated, host inquires for available resources and if found, it will reserve them for the process.

(b) Pre Copy: All the pages are sent to the new node while the guest OS still continues the execution of the application. The changes made during this time are sent as dirty bits so that they can be identified on the new node.

\section{Analyzing performance}

After all configurations, we analyzed the performance of our virtual distributed computing environment. We manage heterogeneous resources, create a virtual computing clusters under the control of a hypervisor and combine computing resources into a single computing system, which shown in figure 5. Without virtualization technologies computing environment inability to control computer processes and dynamic load balancing between nodes to improve performance during execution of parallel and multi-threaded applications.

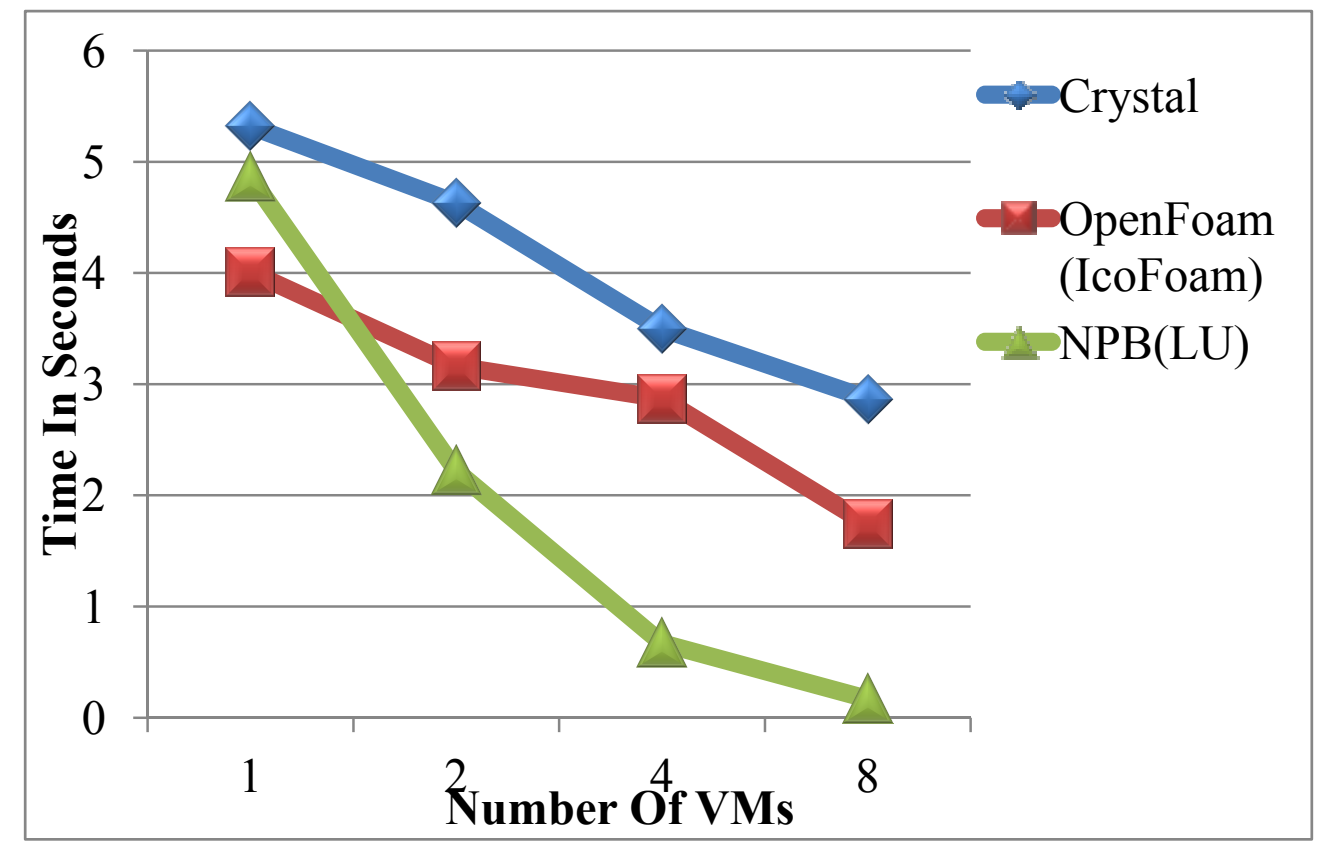

Fig. 6. Performance Testing On Virtual Computing Environment

\section{Conclusion}

Virtualization, that is increasingly attractive for commercial systems, as implemented by a small hypervisor that runs below the usual OS layer, has the same potential to benefit HPC applications in the dimensions of flexible OS variety, productivity, performance, reliability, availability, security and simplicity. Combination of virtualization and single system image allows processes to more easily migrate between nodes in the cluster for better load balancing and effectiveness of the computing environment [Mergen et al., 2003].

\section{References}

Al-Kiswany S., Subhraveti D., Sarkar P. and Ripeanu M. VMFlock: Virtual machine co-migration for the cloud. In HPDC'11 (San Jose, USA, June 2011). 
Desai M. Department of Computer Science, University of Southern California Los Angeles, CA. High Performance Computing and Virtualization, 2012.

Litty L. "Hypervisor-based Intrusion Detection," M.S. thesis, Dept. Computer Science, University of Toronto, 2005.

Mergen M. F., Uhlig V., Krieger O., Xenidis J. Virtualization for high performance. 2003.

Nagarajan A. B., Mueller F., Engelmann Ch., Scott S. L. Proactive fault tolerance for HPC with Xen virtualization. ICS 2007: 23-32.

Rajkumar Buyya T. C. "Single system image (ssi)," the International Journal of High Performance Computing Applications, vol. 15, pp. 124-135, 2001.

Sabahi F. Secure Virtualization for Cloud Environment Using Hypervisor-based Technology, 2012.

Yong L. Network Center of Nanchang University, Single System Image with Virtualization Technology for Cluster Computing Environment, Nanchang 330031, China. 